\title{
Computational modelling and experimental verification of the effective thermal conductivity of hollow bricks
}

\author{
J. Kočí, J. Maděra, L. Fiala \& R. Černý \\ Department of Materials Engineering and Chemistry, Faculty of Civil \\ Engineering, Czech Technical University in Prague, Czech Republic
}

\begin{abstract}
The effective thermal conductivity of hollow brick blocks filled with different insulation materials is analyzed using a combination of experimental and computational approaches. In the experimental part, thermal properties of brick body, mineral wool and expanded polystyrene are measured and a semi-scale experiment is performed to determine heat fluxes and temperature distributions across the brick. Based on the semi-scale experimental results, computer simulations are carried out and the thermal parameters of the materials filling the brick cavities are optimized. Finally, the effective thermal conductivity of hollow brick block is determined.

Keywords: hollow brick block, computer simulation, polystyrene, mineral wool, filling, optimisation.
\end{abstract}

\section{Introduction}

Reducing energy consumption and eliminating wastage are among the main goals of the European Union (EU). EU support for improving energy efficiency will prove decisive for competitiveness, security of supply and for meeting the commitments on climate change made under the Kyoto protocol. There is significant potential for reducing consumption with cost-effective measures. With $40 \%$ of energy consumed in buildings, the EU has introduced legislation to ensure lower energy consumption. The key part of this legislation is Energy Performance of Buildings Directive (EPBD, directive 2002/91/EC) [1], which was first published in 2002. This directive required all EU countries to enhance 
their building regulations and to introduce energy certification schemes for buildings.

In 2010 there was introduced new adoption of recast EPBD (Directive 2010/31/EU) [2], which toughened the regulations given by original EPBD. The EU Members are facing new tough challenges, among them moving towards new and retrofitted nearly-zero energy buildings by 2020 (2018 in the case of public buildings), the application of cost-optimal methodology for setting minimum requirements for both envelope and technical systems.

These increasing requirements to the energy consumption and energy efficiency of the buildings led the building material producers to develop new materials that will find its use in low-energy and in the future to nearly-zero energy buildings.

As the crucial role in these kinds of buildings is played by thermal insulation systems, also the load bearing structures should meet high demands on thermal insulation properties. This is the reason why hollow brick blocks have appeared on the European building ceramics market and have practically replaced the traditional solid bricks. However, the development of the new types of bricks was very fast and their thermal properties were improved in more or less intuitive way. Experiments in steady state conditions then either confirmed the expected values of effective thermal conductivity or showed a failure in a trialand-error process.

In recent time there appeared new types of hollow brick block. As the original brick blocks contain cavities filled with air, the new types are filled with different insulation materials, such as mineral wool or expanded polystyrene. At first glance, this innovation seems to be useless, as the thermal insulation of the dry static air is lower than common thermal insulation materials. But it is important to notice, that when the cavities are filled with solid materials, the heat transfer by radiation is negligible and thus the total effective heat transfer of new types of hollow brick blocks may be lower than traditional hollow brick block filled with air.

In this paper, a combined experimental-computational approach is applied for the determination of effective thermal conductivity of hollow brick blocks with the cavities filled with hydrophobic mineral wool and expanded polystyrene. At first, the large semi-scale experiment with hollow brick block was conducted in different temperature conditions on exterior and interior side. Such experiment provided heat fluxes on exterior and interior side of brick block, as well as temperature distribution across the block. Finally, the finite element approach was applied to fit the measured heat fluxes and temperatures, in order to determine the effective thermal conductivity of hollow brick block.

\section{Experimental}

\subsection{Setup of the semi-scale experiment}

For the realisation of semi-scale experiment, a testing device described in $[3,4]$ was used. It consisted of climatic chamber system that enabled simulation of 
difference climate conditions of a building envelope sample with the real thickness of all its components. In the tested structure, continuous monitoring of temperature was performed. For temperature monitoring commercially produced sensors by Ahlborn were employed. The accuracy of resistance thermometers was $\pm 0.4^{\circ} \mathrm{C}$ in the temperature range from $-20^{\circ} \mathrm{C}$ to $0^{\circ} \mathrm{C}$, and $\pm 0.1{ }^{\circ} \mathrm{C}$ in the temperature range from $0^{\circ} \mathrm{C}$ to $70^{\circ} \mathrm{C}$. The heat flux was monitored by the heat flux plate sensors Ahlborn FQA020C of cylindrical shape having diameter $33 \mathrm{~mm}$. The accuracy of these sensors was $\pm 5 \%$ of the measured value.

The climatic chamber system consists of two climatic chambers, connected by a specially developed tunnel for testing of large specimens. The construction of the particular chambers is based on common commercial solutions for controlling temperature and relative humidity conditions, but the solution of connecting tunnel between the chambers and the organization of additional admission holes for parallel measurements are specific. The organization of the experiment is shown schematically in Fig. 1, the real measuring device is presented in Fig. 2.

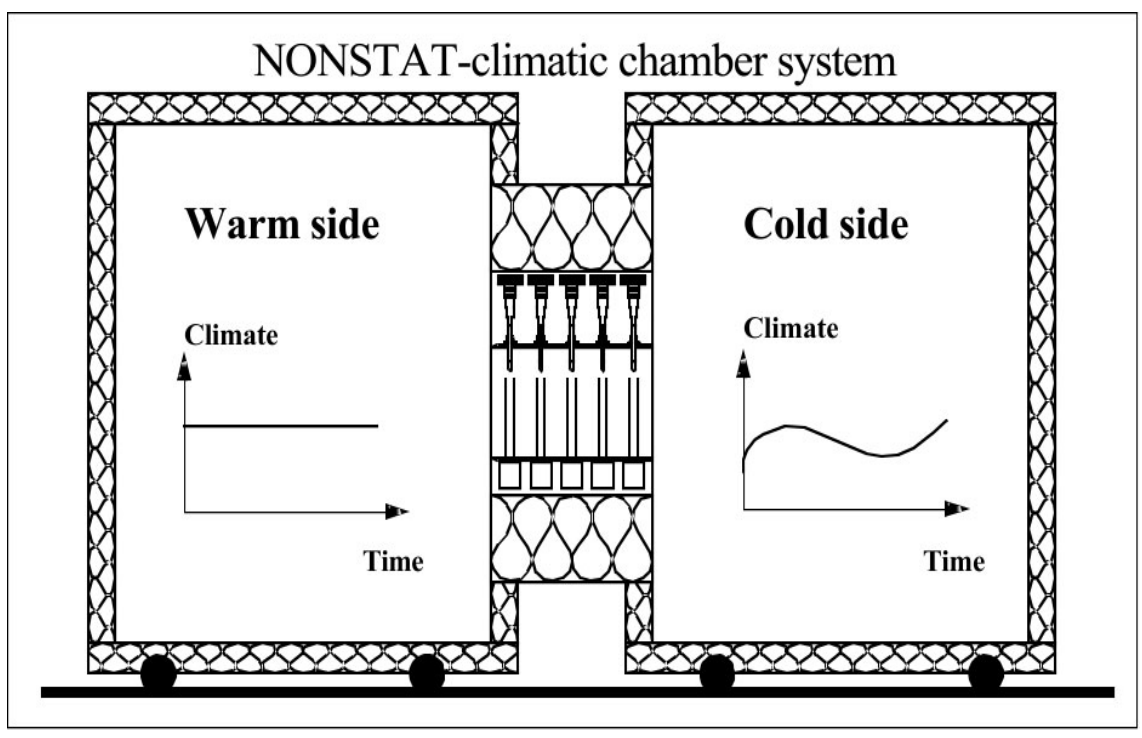

Figure 1: $\quad$ Scheme of the semi-scale measuring device.

During the experiment constant values of temperature and relative humidity were maintained for exterior and interior. For the exterior the temperature was held at $30 \pm 1{ }^{\circ} \mathrm{C}$ and for interior at $15 \pm 1{ }^{\circ} \mathrm{C}$. The relative humidity was constant at $30 \pm 2 \%$. The sensor placing is shown in Fig. 3. In total we used 4 plate sensors for heat flux monitoring (HF1-4), 4 sensors for monitoring exterior and interior temperature and 12 sensors for monitoring the temperature within the hollow brick block (1-7 for polystyrene filling, VIII-XII for mineral wool filling).

The dimensions of hollow brick block are $500 \times 247 \times 249 \mathrm{~mm}$. 


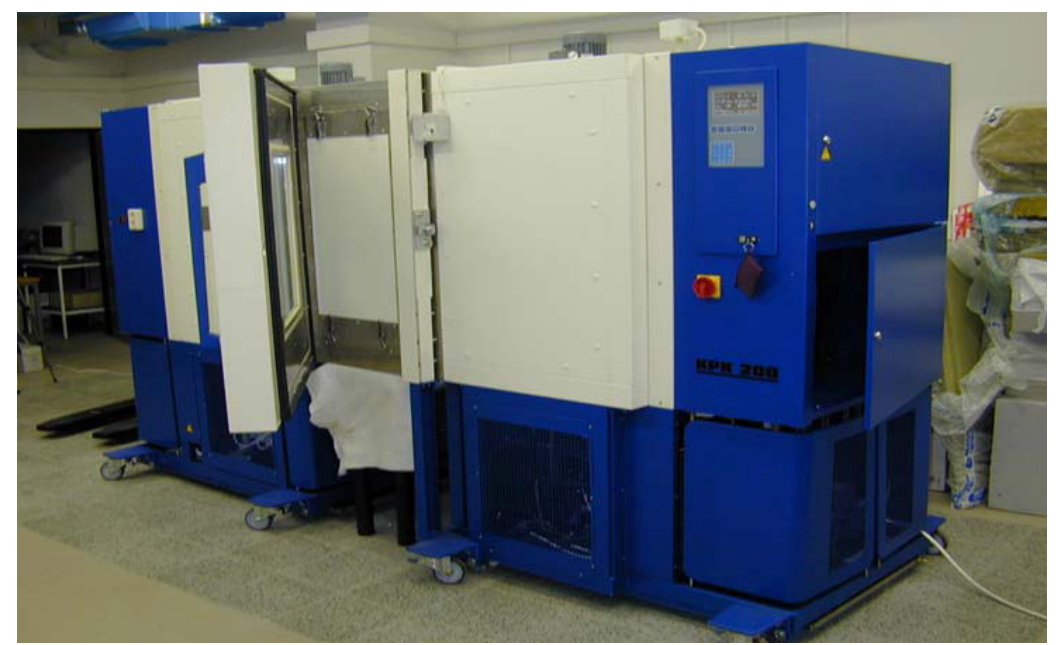

Figure 2: The semi-scale measuring device.

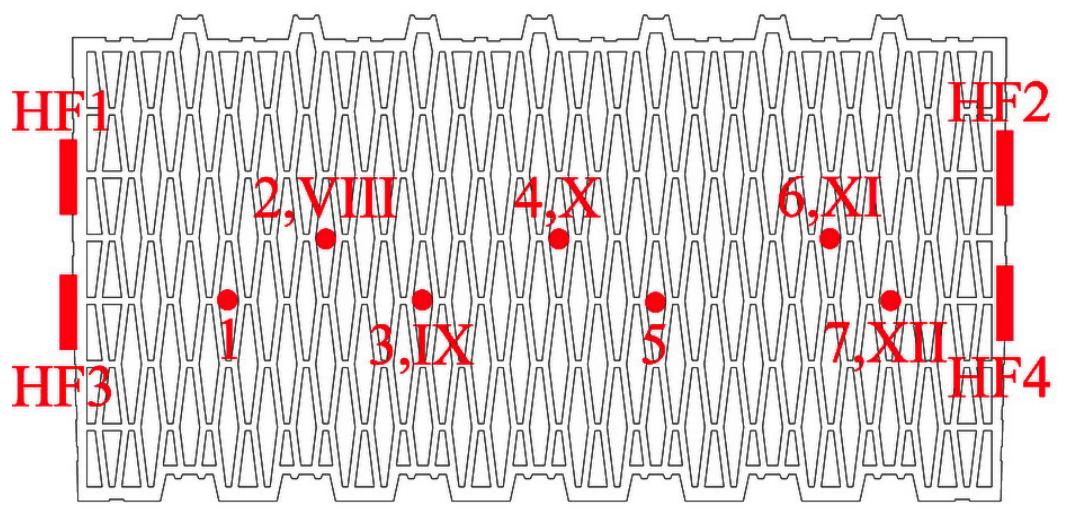

Figure 3: Sensors placement in the hollow brick block.

\subsection{Material characteristics}

The data for basic physical properties of brick body were obtained by helium pycnometry and by the gravimetric method. The bulk density was $1389 \mathrm{~kg} / \mathrm{m}^{3}$, the matrix density $2830 \mathrm{~kg} / \mathrm{m}^{3}$, and the open porosity $0.509 \mathrm{~m}^{3} / \mathrm{m}^{3}$. The thermal conductivity in dry state determined using the impulse method (Isomet 2104) was $0.30 \mathrm{~W} / \mathrm{mK}$. The thermal conductivity of expanded polystyrene was $0.039 \mathrm{~W} / \mathrm{mK}$ [5]. The thermal conductivity of mineral wool is dependent on its bulk density. The bulk density of mineral wool contained in the cavity was calculated as $102 \mathrm{~kg} / \mathrm{m}^{3}$, so the thermal conductivity according to [6] was $0.045 \mathrm{~W} / \mathrm{mK}$. 


\subsection{Experimental results}

The experimental measurements were accomplished for two types of brick blocks that were placed into the measuring device at the same time - one brick was filled with mineral wool, the other brick with expanded polystyrene. For both types the heat fluxes on cold and hot side were recorded and the average values were calculated. The same was done for exterior and interior temperature. The experimental results are summarized in Tables 1 and 2.

Table 1: $\quad$ Experimental results for hollow brick block filled with polystyrene.

\begin{tabular}{|l|l|l|}
\hline Heat flux - exterior & -2.3230 & $\mathrm{~W} / \mathrm{m}^{2}$ \\
\hline Heat flux - interior & 2.2436 & $\mathrm{~W} / \mathrm{m}^{2}$ \\
\hline Average heat flux & $\mathbf{2 . 2 8 3 3}$ & $\mathbf{W} / \mathbf{m}^{2}$ \\
\hline Avg. exterior temperature & 15.43 & ${ }^{\circ} \mathrm{C}$ \\
\hline Avg. interior temperature & 30.65 & ${ }^{\circ} \mathrm{C}$ \\
\hline
\end{tabular}

Table 2: Experimental results for hollow brick block filled with mineral wool.

\begin{tabular}{|l|l|l|}
\hline Heat flux - exterior & -1.9035 & $\mathrm{~W} / \mathrm{m}^{2}$ \\
\hline Heat flux - interior & 2.3153 & $\mathrm{~W} / \mathrm{m}^{2}$ \\
\hline Average heat flux & $\mathbf{2 . 1 0 9 4}$ & $\mathbf{W} / \mathbf{m}^{2}$ \\
\hline Avg. exterior temperature & 15.43 & ${ }^{\circ} \mathrm{C}$ \\
\hline Avg. interior temperature & 30.65 & ${ }^{\circ} \mathrm{C}$ \\
\hline
\end{tabular}

\section{Computational}

The main objective of the computational part of the experiment was to optimize the heat fluxes and temperature distribution across the hollow brick block in order to determine the effective thermal conductivity of the system. For this purpose some advance optimization method should be used, for example genetic algorithms [7], but in this case we used simple trial-and-error method.

For the calculation of heat transfer finite element method was used. The computational simulations were performed without taking into account any heat loss, i.e., the hollow brick block was supposed to be very well insulated on lateral sides. The average exterior and interior temperatures measured during the experiment, $30.65{ }^{\circ} \mathrm{C}$ and $15.43{ }^{\circ} \mathrm{C}$, were used as the Newton's boundary conditions, in order to make possible a direct comparison of computational and experimental data.

All simulations were performed for steady-state heat transfer using the Fourier's law, defined as

$$
q=-\lambda \frac{d T}{d x},
$$

where $q$ is heat flux $\left[\mathrm{W} / \mathrm{m}^{2} \mathrm{~K}\right]$ and $\lambda$ is thermal conductivity $[\mathrm{W} / \mathrm{mK}]$. 
The effective thermal conductivity of the hollow brick block $\lambda_{\text {eff }}$, was calculated using the equation

$$
\lambda_{\text {eff }}=q \frac{\Delta x}{\Delta T},
$$

where $\Delta x[\mathrm{~m}]$ is the total thickness of the brick block $(0.5 \mathrm{~m}), \Delta T[\mathrm{~K}]$ is the temperature difference between hot and cold face of the brick block, and $q\left[\mathrm{~W} / \mathrm{m}^{2}\right]$ is the heat flux in the boundary element of the hollow brick block calculated according to

$$
q=\lambda_{b b} \frac{\Delta T_{e}}{\Delta x_{e}},
$$

where $\lambda_{b b} \quad[\mathrm{~W} / \mathrm{mK}]$ is the thermal conductivity of the brick body $\left(\lambda_{b b}=0.300 \mathrm{~W} / \mathrm{mK}\right), \Delta x_{e}[\mathrm{~m}]$ is the thickness of the boundary element $(\Delta x=0.001 \mathrm{~m})$, and $\Delta T_{e}[\mathrm{~K}]$ is the temperature difference between the opposite sides of the rectangular element in the direction of the heat flux.

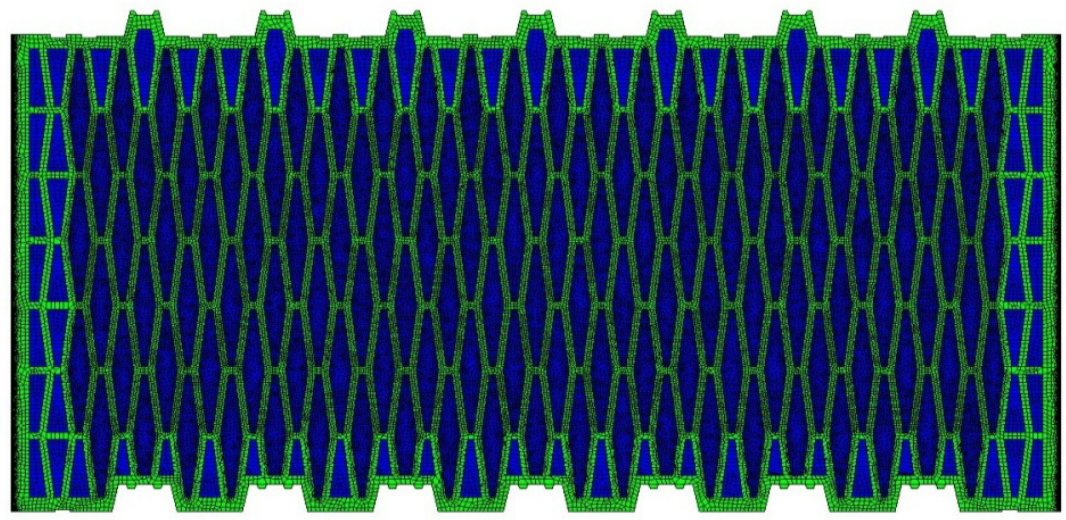

Figure 4: Detail of meshed brick body including cavities.

The whole optimization process is described in following steps:

1. The hollow brick block including cavities was meshed and the materials were assigned to respective elements. The mesh consisted in total of 78687 nodes and 77819 quadrilateral elements (see Fig. 4)

2. As the computer simulations were assumed as steady state, the average heat flux was calculated from heat fluxes on hot and cold face of the hollow brick block. The average flux of brick block filled with polystyrene is $2.2833 \mathrm{~W} / \mathrm{m}^{2}$ and average heat flux brick block filled with mineral wool is $2.1094 \mathrm{~W} / \mathrm{m}^{2}$. 
3. Next, the first simulations were carried out with standard values of thermal conductivities of filling materials declared by producers for dry state $\left(\lambda_{E P S}=0.039 \mathrm{~W} / \mathrm{mK}, \lambda_{M W}=0.045 \mathrm{~W} / \mathrm{mK}\right)$. These values were fitted in subsequent steps. The thermal conductivity of brick body was fixed during whole optimization process to $0.300 \mathrm{~W} / \mathrm{mK}$. The heat transfer coefficient on the surface of the brick was defined according to Czech National Standard as $7.69 \mathrm{~W} / \mathrm{m}^{2} \mathrm{~K}$ [8]. Simulation results of this phase are shown in Tables 3 and 4, row 1.

Table 3: Optimization process of hollow brick block filled with expanded polystyrene.

\begin{tabular}{|c|c|c|c|c|c|}
\hline & $\begin{array}{c}\lambda_{E P S} \\
{[\mathrm{~W} / \mathrm{mK}]}\end{array}$ & $\begin{array}{c}\alpha \\
{\left[\mathrm{W} / \mathrm{m}^{2} \mathrm{~K}\right]}\end{array}$ & $\begin{array}{c}q \\
{\left[\mathrm{~W} / \mathrm{m}^{2}\right]}\end{array}$ & $\begin{array}{c}\lambda_{\text {eff }} \\
{[\mathrm{W} / \mathrm{mK}]}\end{array}$ & $\begin{array}{c}\max \Delta T \\
{\left[{ }^{\circ} \mathrm{C}\right]}\end{array}$ \\
\hline 1. & 0.039 & 7.69 & 2.1985 & 0.0753 & 0.88 \\
\hline 2. & 0.0414 & 7.69 & 2.2818 & 0.0783 & 0.82 \\
\hline 3. & 0.0414 & 3.00 & 2.1493 & 0.0782 & 0.44 \\
\hline $\mathbf{4 .}$ & $\mathbf{0 . 0 4 5 8}$ & $\mathbf{3 . 0 0}$ & $\mathbf{2 . 2 8 1 8}$ & $\mathbf{0 . 0 8 3 6}$ & $\mathbf{0 . 4 4}$ \\
\hline
\end{tabular}

Table 4: Optimization process of hollow brick block filled with mineral wool.

\begin{tabular}{|c|c|c|c|c|c|}
\hline & $\begin{array}{c}\lambda_{E P S} \\
{[\mathrm{~W} / \mathrm{mK}]}\end{array}$ & $\begin{array}{c}\alpha \\
{\left[\mathrm{W} / \mathrm{m}^{2} \mathrm{~K}\right]}\end{array}$ & $\begin{array}{c}q \\
{\left[\mathrm{~W} / \mathrm{m}^{2}\right]}\end{array}$ & $\begin{array}{c}\lambda_{\text {eff }} \\
{[\mathrm{W} / \mathrm{mK}]}\end{array}$ & $\begin{array}{c}\max \Delta T \\
{\left[{ }^{\circ} \mathrm{C}\right]}\end{array}$ \\
\hline 1. & 0.045 & 7.69 & 2.4043 & 0.0827 & 0.69 \\
\hline 2. & 0.0365 & 7.69 & 2.1100 & 0.0722 & 0.70 \\
\hline 3. & 0.0365 & 3.00 & 1.9968 & 0.0721 & 0.49 \\
\hline $\mathbf{4 .}$ & $\mathbf{0 . 0 3 9 8}$ & $\mathbf{3 . 0 0}$ & $\mathbf{2 . 1 0 8 2}$ & $\mathbf{0 . 0 7 6 2 9}$ & $\mathbf{0 . 4 8}$ \\
\hline
\end{tabular}

4. The thermal conductivities of filling materials were fitted in order to get better agreement between measured and simulated heat flux through the hollow brick block. Simulation results are summarized in Tables 3, 4, row 2.

5. Next, after achieving agreement between measured and simulated heat fluxes, the temperature distribution was optimized by modifying the heat transfer coefficient. Simulation results of this phase are shown in Tables 3 and 4 , row 3 .

6. Finally, the agreement between heat flux and temperature distribution of measured and simulated data was achieved by re-optimization of thermal conductivities of filling materials. The final results of whole optimization process are shown in Tables 3 and 4, row 4. The comparison of measured and simulated data from the last optimization step is shown in Figs. 5 and 6 . 


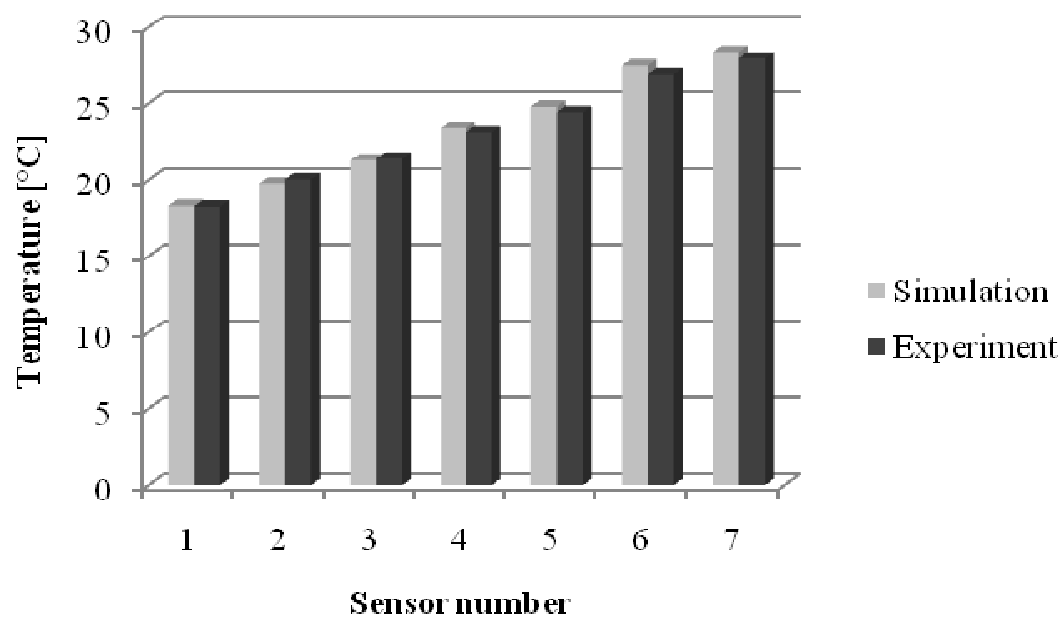

Figure 5: Comparison of simulated and measured data for hollow brick block filled with expanded polystyrene.

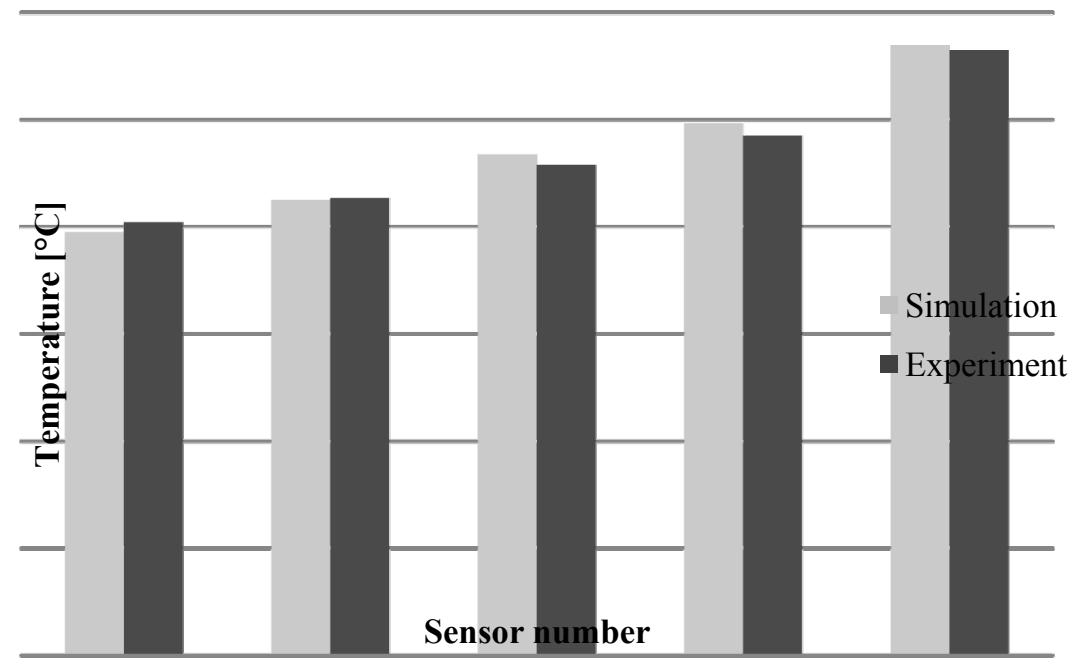

Figure 6: Comparison of simulated and measured data for hollow brick block filled with mineral wool. 


\section{Discussion}

Results of experimental and computational analysis proved that cavity filling significantly influences the effective thermal conductivity of hollow brick blocks. Assuming that experimental measurements were performed with high accuracy, the results of numerical simulations provided very precise information about effective thermal conductivity.

In order to bring the computer simulation closer to the reality, it was necessary to fit heat transfer coefficient between brick surface and surrounding environment of climatic chambers. This coefficient is dependent on temperature and relative humidity of the air, air flow and material of brick body. According to Czech National Standard CSN 73 0540-03, Thermal protection of buildings, Part 3: Design Value Quantities [8] the value of heat transfer coefficient for vertical walls is equal to $7.69 \mathrm{~W} / \mathrm{m}^{2}$. This value was set as initial in first phase of optimization, but during the optimization process it was lowered. Such lowered value was substantiated by the different environmental conditions in the climatic chamber as compared with the normal interior or exterior conditions; the air flow was slower, and the relative humidity was lower.

The average heat flux for hollow brick block filled with expanded polystyrene was measured as $2.2833 \mathrm{~W} / \mathrm{m}^{2}$. In case of using the standard values of thermal conductivity of expanded polystyrene defined by producers $(0.039 \mathrm{~W} / \mathrm{mK}$ for flat insulation boards), the difference between simulated and measured heat fluxes was $3.7 \%$. Even if the difference is almost inconsiderable, its impact on total effective thermal conductivity remains quite high. Therefore, the thermal conductivity of expanded polystyrene had to be modified to $0.0458 \mathrm{~W} / \mathrm{mK}$, which reduced the difference between measured and simulated heat fluxes to $0.1 \%$. The increase of thermal conductivity of expanded polystyrene can be simply explained by different technological production process for hollow brick blocks than for standard insulation boards. In the cavities there are space restrictions for expansion of the polystyrene and therefore there is higher pressure when the pore system is being formed. Therefore, the total porosity of the polystyrene filling is lower and the pores are smaller. The effective thermal conductivity of hollow brick block filled with expanded polystyrene with $0.1 \%$ error in heat fluxes was determined as $0.0836 \mathrm{~W} / \mathrm{mK}$.

Contrary to the polystyrene filling, the thermal conductivity of mineral wool filling was decreased during optimization process. In the first phase of optimization procedure the thermal conductivity was estimated based on bulk density of mineral wool extracted directly from the cavity. Such approach should bring some initial error to the simulations (the difference between simulated and measured heat flux in the first phase of optimization was $13.9 \%$ ), because the direct measurement of thermal conductivity of mineral wool was not performed. Therefore, in subsequent simulation steps the thermal conductivity of mineral wool had to be modified in order to find match between simulated and measured heat fluxes. After final iteration the total difference in heat fluxes was reduced under $0.1 \%$ and the effective thermal conductivity of hollow brick block filled 
with mineral wool was determined as $0.0763 \mathrm{~W} / \mathrm{mK}$. The thermal conductivity of mineral wool was considered as $0.0398 \mathrm{~W} / \mathrm{mK}$.

\section{Conclusions}

Based on the results obtained in this paper, it can be concluded that the current trend of development of hollow brick blocks aimed at the improvement of their thermal insulation properties by filling the cavities with different materials than air is prospective. By proper choice of filling material the effective thermal conductivity of the system can be improved. Comparing the results of computer simulations, the hollow brick block with cavities filled with mineral wool exhibited better thermal performance than expanded polystyrene filling. The further research of hollow brick blocks should be aimed at increasing the precision of heat flux measurement in the experimental part and involving more advanced optimization methods in numerical solutions, such as genetic algorithms.

\section{Acknowledgement}

This research has been supported by the Czech Science Foundation, under project No P105/12/G059.

\section{References}

[1] European Union, Directive 2002/91/EC of the European Parliament and of the Council of 16 December 2002 on the energy performance of buildings, Official Journal of the European Communities (December 2002).

[2] European Union, Directive 2010/31/EC of the European Parliament and of the Council of 19 May 2010 on the energy performance of buildings, Official Journal of the European Communities (June 2010).

[3] Pavlík, Z., Pavlík, J., Jiřičková, M. and Černý, R. System for testing the hygrothermal performance of multi-layered building envelopes. Journal of Thermal Envelope and Building Science, 25, pp. 239-249, 2002.

[4] Pavlík, Z., Černý, R. Experimental Assessment of Hygrothermal Performance of an Interior Thermal Insulation System Using a Laboratory Technique Simulating On-Site Conditions. Energy and Buildings, 40, pp. 673-678, 2008.

[5] Kočí, V., Jerman, M., Černý, R. Hygric and Thermal Properties of Materials Involved in the Envelopes of Contemporary Buildings. Modern Methods and Advances in Structural Engineering and Construction, Singapore: Research Publishing Services, pp. 807-812, 2011.

[6] Jiřičková, M. and Černý, R., Effect of Hydrophilic Admixtures on Moisture and Heat Transport and Storage Parameters of Mineral Wool. Construction and Building Materials, 20, pp. 425-434, 2006. 
[7] CSN 730540 - 03. Thermal protection of buildings - Part 3: Design value quantities, Czech Office for Standards, Metrology and Testing, 2005.

[8] Kočí, J., Žumár, J., Pavlík, Z, Černý R. Application of Genetic Algorithm for Determination of Water Vapor Diffusion Parameters of Building Materials. Journal of Building Physics, 35, pp. 238-250, 2012. 